\title{
LINEAMIENTOS DE LA SENTENCIA BAJO EL MODELO SOCIAL DE DISCAPACIDAD
}

\author{
SENTENCING GUIDELINES UNDER THE SOCIAL DISABILITY MODEL
}

$$
\text { Dianelly Trinidad-de-la-O }{ }^{1} * \text { (D). }
$$

1. Escuela Judicial del Poder Judicial del Estado de Tabasco, México. dianellytrinidad@gmail.com

* Autor de correspondencia: Dianelly Trinidad-de-la-O, correo electrónico: dianellytrinidad@gmail.com

\section{RESUMEN}

Este artículo describe el modelo social de discapacidad, sus antecedentes y alcances en el sistema jurídico. Tiene como objetivo proporcionar lineamientos para que el operador jurídico identifique si es necesario realizar ajustes razonables al dictar sentencia en el procedimiento judicial, definiendo y ejemplificando cada uno de estos.

Palabras clave: Ajustes razonables; modelo social de discapacidad; personas con diversidad funcional; sentencia con formato de lectura fácil.

\begin{abstract}
This article describes the social model of disability, its antecedents and scope in the legal system. Its objective is to provide guidelines for the legal operator to identify whether it is necessary to make reasonable adjustments when passing judgment in the judicial procedure, defining and exemplifying each of these.
\end{abstract}

Keywords: Reasonable accommodation; social model of disability; people with functional diversity; easy-to-read sentence.

Cómo citar:

Trinidad-de-la-O, Dianelly. (2021). Lineamientos de la sentencia bajo el modelo social de discapacidad. Revista de Investigaciones Universidad del Quindio, 33(S2), 147-161. https://doi. org/10.33975/riuq.vol33nS2.627 


\section{INTRODUCCIÓN}

Todas las personas, tienen derecho al acceso a la justicia, es decir, pueden acudir a los tribunales para ejercitar una acción (derecho a la acción procesal) u oponer una excepción (derecho de defensa o garantía de audiencia), según sea su caso, y la autoridad debe impartir justicia en los términos y plazos que fija la Ley, tal y como lo establecen los artículos 17 de la Constitución Política de los Estados Unidos Mexicanos y 8 y 25 de la Convención Americana sobre Derechos Humanos.

Al iniciar estos juicios o procedimientos, los ciudadanos esperan que la Autoridad resuelva sus pretensiones de forma definitiva a través de una determinación judicial llamada sentencia.

Gómez Lara, Cipriano (2005) define a la sentencia como: “el acto final del proceso, acto aplicador de la ley sustantiva a un caso concreto controvertido para solucionarlo o dirimirlo"

Entonces, la sentencia puede ser definida como un acto de los operadores jurídicos, en el que, en un término legal y a través de un documento, después de valorar las pruebas aportadas por las partes, de carácter fundada y motivada, decide de forma definitiva la solución de cada uno de los problemas puestos bajo su consideración.

Las personas con diversidad funcional, al igual que las personas estándar, pueden iniciar un juicio o procedimiento frente a la autoridad jurisdiccional esperando el mismo resultado: se emita una sentencia de manera pronta, completa e imparcial.

Si bien, en los últimos años se ha reformado la ley con la finalidad de que el ordenamiento jurídico privilegie que las sentencias sean emitidas sin tecnicismos y con lenguaje ciudadano, ello no es suficiente para las personas con discapacidad.

Por ejemplo, una persona con diversidad funcional mental, visual o auditiva, al recibir la sentencia tradicional, poco o nada podrá conocer o comprender la decisión de la autoridad jurisdiccional, enfrentándose así a una barrera que genera discapacidad, puesto que, para que sea accesible para la persona, deben de realizarse ajustes razonables acorde a sus necesidades específicas con la finalidad de que tenga conocimiento de la resolución y sus alcances, surgiendo la necesidad de realizar ajustes razonables como lo son las sentencias con formato de lectura fácil.

En caso contrario, únicamente la personas que pueden ver, escuchar y comprender de manera estándar, es decir como la mayoría de la gente sin alguna condición específica, podrán tener conocimiento del resultado del fallo emitido por el operador jurídico, debido a que la sentencia tradicional no se encuentra diseñada para que su contenido sea accesible a todas las personas, es decir, no atiende a la diversidad humana.

Si bien, el operador jurídico conoce los requisitos legales de la sentencia tradicional, pues tiene a su alcance el ordenamiento jurídico que la prevé, por ejemplo, en el estado de Tabasco, la sentencia se encuentra regulada en la legislación local y de conformidad con los artículos 126, 127 y 323 del Código de Procedimientos Civiles en vigor para el estado de Tabasco (CPCT, 1997), los requisitos de las sentencias son: nombre del tribunal que la dicte, lugar y fecha, nombre de las partes, relación sucinta de las cuestiones planteadas, análisis y valoración de las pruebas, motivación y fundamentación legal, la determinación judicial resolviendo con toda precisión todos los puntos sujetos a consideración, 
puntos resolutivos y firma del juez y la autorización del secretario, aunado a que esta debe emitirse, dentro del término que señala la ley.

De este modo, es claro que el operador jurídico sabe que es una sentencia, sus requisitos y en qué casos se emite la sentencia tradicional, lo que no ocurre, con los ajustes razonables que debe de realizar al emitirla.

Es por ello, que lo que se pretende con este artículo es explicar desde la historia crítica el modelo social de discapacidad y mediante la doctrina analítica cuales son los alcances del modelo social de discapacidad y los lineamientos que el operador jurídico debe considerar al realizar ajustes razonables, dentro de los cuales se encuentran: las sentencias con formato de lectura fácil.

\section{MODELO SOCIAL DE DISCAPACIDAD.}

A lo largo de la historia, la discapacidad ha tenido tres modelos de tratamiento: el modelo prescindencia, el modelo rehabilitador y el modelo social.

\section{a. Antecedentes del modelo social de discapacidad: el modelo de prescindencia y el modelo rehabilitador.}

\section{- El modelo de prescindencia}

El modelo de prescindencia, la justificación de la discapacidad es mayormente religiosa, ya que se considera que es un castigo de los dioses por un pecado cometido por los padres, o un presagio de una catástrofe; en el ámbito social, se considera que la persona con discapacidad no tiene nada que aportar a la comunidad ya que se toma a la persona como un ser improductivo, una carga que debe ser llevada por los padres y la comunidad. Este modelo se divide en dos submodelos: el eugenésico y el de marginación. (Palacios, 2008)

- Submodelo eugenésico considera que la persona con discapacidad no merece vivir la vida y como consecuencia, cuando se detecta que un menor tiene diversidades funcionales congénitas, se prescinde de esta persona mediante prácticas eugenésicas, no respetando su derecho a la vida. Es en este submodelo, podemos encontrar las prácticas de exterminio de recién nacidos que no cumplían con los cánones físicos exigidos por el Estado en la antigua Roma, Grecia, o Esparta.

En cambio, si la diversidad funcional surge después del nacimiento, se les otorga un tratamiento diferente a las personas, otorgando muchas ayudas con fines de subsistencia, sin embargo, los que no tenían acceso a éstas, su único medio para obtener recursos económicos para subsistir era ser objeto de burla o diversión (Palacios, 2008).

- El submodelo de marginación tiene como característica principal la exclusión, es la respuesta social que genera la discapacidad, ya sea por menosprecio o miedo. Contrario al submodelo eugenésico, en este no se comete infanticidio, sin embargo, "gran parte de las personas discapacitadas fallecen por el descuido de sus cuidadores o el abandono, ello en virtud de que la subsistencia de estos suelen ser la caridad, mendicidad u objeto de burla" (Palacios, 2008). 


\section{- Modelo rehabilitador.}

En este modelo, la discapacidad se funda en que la condición de las personas es médica, que tiene un origen biológico, por lo que la medicina y los médicos son los que deben de curar o rehabilitar para que sean como la mayoría de la comunidad: estándar, aunado a que en la estructura social y en la medida que pueden o no ser rehabilitados van a ser aceptados por la comunidad.

Bajo esta perspectiva se crean distintos programas gubernamentales de apoyo, pues no se busca que estas personas con sus condiciones específicas entren al mercado laboral y puedan allegarse a sus recursos, si no bien, se crean políticas asistencialistas subestimando su capacidad de producir sus propios medios de subsistencia.

El modelo rehabilitador posee dos características: la primera, las causas que fundan la discapacidad son científicas en términos de salud o enfermedad; y la segunda, referente a que las personas con discapacidad pueden aportar a la comunidad en la medida que sean rehabilitadas o normalizadas. Afirma pues que las personas con discapacidad serán "rentables" pero esta rentabilidad estará supeditada a que esta logre asimilarse a los demás "válidos y capaces”. (Palacios, 2008)

En este modelo, el uso de dictámenes médicos prolifera, ya que son mediante estos en que se determina la discapacidad y se incapacita a las personas, dejando de lado su voluntad y deseos para que estos sean ejercidos por terceras personas.

\section{b. Modelo social de discapacidad.}

El modelo social, establece que las causas que originan la discapacidad son sociales, es decir, no son las limitaciones de las personas el problema, sino las limitaciones de la sociedad cuando prestan servicios sin asegurarse que las necesidades de todas las personas están previstas dentro de la organización social. Una persona con discapacidad, bajo este modelo, se basa más en las limitaciones de la sociedad, que en la propia limitación de la persona. (Palacios, 2008)

En este modelo, la discapacidad no es una característica de la persona, sino el conjunto de circunstancias creadas por el ambiente social; sostiene que la colectividad tiene que actuar con responsabilidad para realizar las modificaciones necesarias para la participación plena de las personas con discapacidad en todos los aspectos de su vida, de este modo, se requiere que se generen cambios sociales y estructurales. (Carreón Castro, 2019)

De este modo, el modelo social surge debido a que los servicios, espacio y la sociedad está diseñada de una manera que no contempla a toda la diversidad humana, sino únicamente en atención a los atributos de la mayoría, personas estándar.

Es por ello, que las personas con diversidad funcional al tratar de acceder a estos servicios, espacios $\mathrm{u}$ otros, se encuentran con una barrera que no les permite ejercer sus derechos, pues no se encuentra contemplada su diversidad funcional, causando discapacidad.

Si bien históricamente se han desarrollado estos tres modelos de discapacidad, ello no quiere decir que ha evolucionado así el pensamiento de la comunidad, pues existen personas que aún tienen la visión de discapacidad bajo el primero o segundo modelo, por lo que es imperativo que se unan esfuerzos para 
generar un cambio de pensamiento en la comunidad.

\section{c. Alcances del Modelo social de discapacidad.}

Es bajo la óptica del modelo social, que se redactó la Convención Internacional sobre los Derechos de las Personas con Discapacidad -CDPD- y su Protocolo Facultativo, instrumentos que fueron aprobados en la Asamblea General de las Naciones Unidas el 13 de diciembre de 2006, siendo la primer Convención de derechos humanos del siglo XXI.

Por su parte, México firmó y ratificó esta Convención que entró en vigor el 3 de mayo de 2008, este documento es vinculante para todas las autoridades.

Según el preámbulo de la CDPD, entre otros, se creó reconociendo la necesidad de proteger los derechos humanos de las personas con discapacidad, reconociendo su diversidad, su dignidad, su valor inherente, libre de distinciones de ninguna especie. Así también, teniendo presente la importancia de que estas tengan accesibilidad en todos los aspectos de su vida para que puedan gozar de todos los derechos humanos y sus libertades fundamentales.

La CDPD pretende alcanzar un objetivo concreto: "Promover, proteger y asegurar el goce pleno y en condiciones de igualdad de todos los derechos humanos y libertades fundamentales para todas las personas con discapacidad, y promover el respeto de su dignidad inherente".

Dentro de los conceptos más importantes que describe la CDPD, se encuentran:

- Discriminación por motivo de discapacidad: Cualquier distinción, exclusión o restricción de derechos por motivo de discapacidad en todos los ámbitos, incluido la denegación de ajustes razonables.

- Ajustes razonables: modificaciones que garantizan que las personas con discapacidad tengan el goce o ejercicio de sus derechos en igualdad de condiciones de los demás y que no impongan una carga desproporcionada o indebida.

- Diseño universal: diseño de productos, entornos, programas y servicios para que todas las personas accedan a estos, sin la necesidad de adaptaciones.

Los principios de la CDPD se encuentran en su artículo 3: a) El respeto de la dignidad inherente, la autonomía individual, incluida la libertad de tomar las propias decisiones, y la independencia de las personas. b) La no discriminación. c) La participación e inclusión plenas y efectivas en la sociedad: d) El respeto por la diferencia y la aceptación de las personas con discapacidad como parte de la diversidad y la condición humanas. e) La igualdad de oportunidades. f) La accesibilidad. g) La igualdad entre el hombre y la mujer. y h) El respeto a la evolución de las facultades de los niños y las niñas con discapacidad y de su derecho a preservar su identidad.

En lo que interesa, las obligaciones de la CDPD para los estados parte, se encuentra promover la formación de personal que trabajan con las personas con discapacidad a fin de prestar un mejor servicio y debe de aplicarse la legislación buscando hacer efectiva la Convención, facilitando en todos los aspectos el ejercicio de los derechos de las personas con discapacidad. 
De igual forma, realza los siguientes derechos:

- Derecho de igualdad y no discriminación: (artículo 5), establece que todas las personas son iguales ante la ley y que debe garantizarse que las personas con discapacidad tengan protección legal y efectiva, por lo que se deben de dictar las medidas pertinentes y asegurar la realización de ajustes razonables.

- Derecho de igual reconocimiento como persona ante la ley: (artículo 12), mismo que refiere que las personas con discapacidad tienen derecho en todas partes al reconocimiento de su personalidad y capacidad jurídica en condiciones de igualdad que las demás personas, teniendo la obligación los estados partes a adoptar medidas para el apoyo que puedan necesitar para su ejercicio, tales como apoyos y salvaguardas.

- Derecho de las personas con discapacidad al acceso a la justicia en igualdad de condiciones de los demás: (artículo 13), estableciendo la obligación de realizar ajustes al procedimiento adecuados para las particulares de la persona, ello para facilitar su plena participación en todos los procedimientos judiciales, aún si se presentan como participantes indirectos.

- Derecho a la libertad de expresión y de opinión y acceso de información: (artículo 21), que incluye que las personas con discapacidad tengan acceso a la información (Berdeja, 2020) de manera oportuna y sin costo adicional, en un formato accesible y con las tecnologías adecuadas a las particularidades de la persona, tales como otorgar la protección más amplia posible a favor de la persona, de conformidad con los principios de universalidad, interdependencia, indivisibilidad y progresividad.

De forma específica, en el caso de mujeres y niñas con discapacidad: advierte se

Hace mención a un aspecto importante de la discapacidad, como lo es la toma de conciencia: de este modo, los estados partes se comprometen a sensibilizar a la sociedad para que se respeten los derechos y la dignidad de las personas, buscando la erradicación de estereotipos, prejuicios y prácticas que conculquen con sus derechos.

Bajo este contexto, es clara la obligación de los operadores jurídicos proteger los derechos de las personas con discapacidad y tomar todas las acciones para que ejerzan sus derechos en igualdad de condiciones.

Aunado a lo anterior, después de la reforma trascendental en materia de derechos humanos de dos mil once, la Constitución de los Estados Unidos Mexicanos (CPEUM) en su artículo $1^{\circ}$ entre otros, señala que todas las autoridades desde el ámbito de su competencia tienen la obligación de promover, respetar, proteger y garantizar los derechos humanos contenidos en la Constitución y en los Tratados Internacionales, dentro de los que se encuentra el CDPD, además, la CPEUM establece que se debe de lengua de señas, braille, medios y formatos aumentativos y alternativos, comunicación accesible. Debe potencializar sus derechos; en el caso de niñas y niños con discapacidad: establece el respeto de su interés superior y de ejercer sus derechos, tales como expresar su opinión en igualdad de condiciones de los demás niños y niñas, debiendo el estado asegurar que sean asistidos para ello. 


\section{AJUSTES RAZONABLES AL DICTAR SENTENCIA EN EL PROCEDIMIENTO JUDICIAL.}

El nuevo paradigma que surgen del modelo social de discapacidad, crean la obligación a través del CDPD para que el operador jurídico vigile que todas las personas tengan acceso a sus derechos de igualdad, acceso a la justicia e información y para ello, el operador jurídico puede, si así lo considera, realizar ajustes razonables.

De este modo, al momento de citar sentencia, el operador jurídico debe valorar si ello basta para que las personas con discapacidad tengan conocimiento del fallo, o si es necesario que sea apoyado mediante un ajuste razonable.

Los lineamientos que se sugieren para identificar si se deben de realizar ajustes razonables al dictar sentencia dentro de un procedimiento judicial en un panorama general se advierten en el siguiente cuadro:

\begin{tabular}{|c|c|c|}
\hline \multirow{5}{*}{$\begin{array}{l}\text { Lineamientos para identificar } \\
\text { si se deben de realizar ajustes } \\
\text { razonables al dictar sentencia } \\
\text { dentro de un procedimiento } \\
\text { judicial }\end{array}$} & $\begin{array}{l}\text { a. Conocer todo el } \\
\text { marco jurídico protector } \\
\text { de las personas con } \\
\text { discapacidad. }\end{array}$ & $\begin{array}{l}\text { En el ámbito internacional } \\
\text { En el ámbito nacional (México) } \\
\text { En el ámbito local (Tabasco) }\end{array}$ \\
\hline & $\begin{array}{l}\text { b. Identificar el tipo de } \\
\text { diversidad funcional. }\end{array}$ & $\begin{array}{l}\text { - Discapacidad Física. } \\
\text { - Discapacidad Mental. } \\
\text { - Discapacidad Intelectual. } \\
\text { - Discapacidad Sensorial. }\end{array}$ \\
\hline & $\begin{array}{l}\text { c. Detectar si existe } \\
\text { una barrera que genere } \\
\text { discapacidad. }\end{array}$ & \\
\hline & $\begin{array}{l}\text { d. Establecer el tipo de } \\
\text { ajuste razonable que } \\
\text { debe de aplicarse. }\end{array}$ & $\begin{array}{l}\text { Ajustes razonables en el caso de } \\
\text { discapacidad mental o intelectual } \\
\text { Ajustes razonables en el caso de } \\
\text { discapacidad sensorial visual. } \\
\text { Ajustes razonables en el caso de } \\
\text { discapacidad sensorial auditiva. } \\
\text { Ajustes razonables concomitantes. } \\
\text { Otros ajustes razonables. }\end{array}$ \\
\hline & $\begin{array}{l}\text { e. Evitar re victimización } \\
\text { o discriminación. }\end{array}$ & \\
\hline
\end{tabular}

Fuente: Elaboración propia

A continuación, se explicará cada uno de los lineamientos mencionados.

\section{a. Conocer todo el marco jurídico protector de las personas con discapacidad.}

El operador jurídico debe conocer y comprender el marco jurídico de las personas con discapacidad en sus tres niveles: internacional, nacional y local, dentro de los que se encuentran principalmente las siguientes: 
En el ámbito internacional:

- Declaración Universal de los Derechos Humanos.

- Convención Americana sobre Derechos Humanos.

- La Convención sobre los derechos de las Personas con Discapacidad y su protocolo facultativo.

- Convención Interamericana para la Eliminación de todas formas de discriminación contra las personas con discapacidad.

En el ámbito nacional (México):

- La Constitución de los Estados Unidos Mexicanos.

- Ley General para la Inclusión de las Personas con Discapacidad

- Ley Federal para Prevenir y Eliminar la Discriminación

En el ámbito local (Tabasco):

- Constitución del estado de Tabasco.

- Ley para prevenir y eliminar la discriminación en el estado de Tabasco.

También se puede apoyar de criterios que se encuentran establecidos en la jurisprudencia, resoluciones judiciales y así como de documentos emitidos por la SCJN que si bien no son vinculantes pueden ser ilustrativos, dentro de los que se encuentra:

- Cuaderno de jurisprudencia: Derechos de las personas con discapacidad.

- Protocolo de actuación para quienes imparten justicia en casos que involucren derechos de personas con discapacidad.

Es imprescindible hacer mención del Amparo en revisión 1368/2015 dictado en trece de marzo de dos mil diecinueve, por la Primera Sala de la SCJN, en la que resuelve un caso de interdicción, ya que en este fallo se estudian los alcances de la CDPD y resulta ilustrativa para todos los operadores jurídicos, ya que la SCJN se pronuncia de forma concreta sobre los ajustes razonables, apoyos, salvaguardas que se puede establecer para que las personas con discapacidad tengan pleno acceso de sus derechos.

\section{b. Identificar el tipo de diversidad funcional.}

De conformidad con el Instituto Nacional de Estadística y Geografía, en los Estados Unidos Mexicanos habitan 7'168,178 personas con discapacidad, en Tabasco habitan 161,110 personas: 78,931 hombres y 82,179 mujeres de todas las edades y con diferentes diversidades funcionales.

Respecto a las personas con discapacidad el artículo 1 de la CDPD, señala: "Las personas con discapacidad incluyen a aquellas que tengan deficiencias físicas, mentales, intelectuales o sensoriales a largo plazo que, al interactuar con diversas barreras, puedan impedir su participación plena y efectiva en la sociedad, en igualdad de condiciones con las demás."

Si bien la CDPD continúa vinculando el término de discapacidad con "deficiencias", considero que ello atiende a los rezagos del modelo rehabilitador, aunado a que se pueden emplear otros términos, como diversidad funcional, ya que de lo contrario seguiremos refiriéndonos a déficit, limitaciones o minusvalía de las personas, lo que puede permear en la continua estereotipación de que las personas son las causantes de la discapacidad. 


\section{Tipos de discapacidad.}

La Ley General para la inclusión de las Personas con Discapacidad, describe los tipos de discapacidad en su artículo 2, mismos que son:

- Discapacidad Física. Es la secuela o malformación que deriva de una afección en el sistema neuromuscular a nivel central o periférico, dando como resultado alteraciones en el control del movimiento y la postura, y que al interactuar con las barreras que le impone el entorno social, pueda impedir su inclusión plena y efectiva en la sociedad, en igualdad de condiciones con los demás;

- Discapacidad Mental. A la alteración o deficiencia en el sistema neuronal de una persona, que aunado a una sucesión de hechos que no puede manejar, detona un cambio en su comportamiento que dificulta su pleno desarrollo y convivencia social, y que al interactuar con las barreras que le impone el entorno social, pueda impedir su inclusión plena y efectiva en la sociedad, en igualdad de condiciones con los demás;

- Discapacidad Intelectual. Se caracteriza por limitaciones significativas tanto en la estructura del pensamiento razonado, como en la conducta adaptativa de la persona, y que al interactuar con las barreras que le impone el entorno social, pueda impedir su inclusión plena y efectiva en la sociedad, en igualdad de condiciones con los demás;

- Discapacidad Sensorial. Es la deficiencia estructural o funcional de los órganos de la visión, audición, tacto, olfato y gusto, así como de las estructuras y funciones asociadas a cada uno de ellos, y que al interactuar con las barreras que le impone el entorno social, pueda impedir su inclusión plena y efectiva en la sociedad, en igualdad de condiciones con los demás.

Las personas con diversidad funcional son un grupo vulnerable, por lo que sus derechos deben de ser reformados con la finalidad de lograr que tengan el acceso en igualdad de condiciones de los demás.

\section{c. Detectar si existe una barrera que genere discapacidad.}

La sentencia tradicional no se encuentra diseñada para que puedan conocerla y comprenderla todas las personas, pues atendiendo al tipo de diversidad funcional que tenga una persona, puede surgir una barrera que cause discapacidad, sin embargo, es necesario que las personas dentro de un juicio conozcan por sí mismas la resolución del operador jurídico, ya que es la única manera de que tengan plena independencia, control y autonomía.

Se entiende como barrera: "Todos aquellos factores en el entorno de una persona que, cuando están presentes o ausentes, limitan el funcionamiento y generan discapacidad" (OMS 2001).

Dicho de otro modo, las barreras son circunstancias, cosas palpables, cosas intangibles, o una condición que no se encuentra diseñadas para personas con una diversidad funcional específica, que hacen que las personas no puedan ejercer sus derechos como una persona que no posee esa diversidad funcional, generando así una discapacidad.

Así, se puede afirmar que las barreras son aquellas circunstancias, acciones o diseños que limitan la accesibilidad de las personas a un servicio o derecho en la misma medida que lo hacen las personas estándar.

En ese sentido, las sentencias tradicionales no representan una barrera para todas las personas con diversidad funcional, por ejemplo, una persona que tenga diversidad funcional física, que lo haga trasladarse en silla de ruedas, puede conocer y comprender el contenido de la sentencia tradicional, 
sin embargo, si se le hace entrega de una sentencia tradicional a una persona con diversidad funcional visual, este documento, sí representa una barrera que limita su capacidad de tener conocimiento del contenido de la resolución dictada por el operador jurídico.

\section{d. Establecer el tipo de ajuste razonable que debe de aplicarse.}

En el caso de que a la autoridad detecte que un caso particular, se presenta una posible barrera que pueda afectar los derechos de una persona con diversidad funcional, debe de realizar una modificación en su actuar de acuerdo con las necesidades específicas para que esté en igualdad de condiciones que las demás, es decir, un ajuste razonable.

De conformidad con el artículo 2 de la CDPD, el ajuste razonable se entiende como: "las modificaciones y adaptaciones necesarias y adecuadas que no impongan una carga desproporcionada o indebida, cuando se requieran en un caso particular, para garantizar a las personas con discapacidad el goce o ejercicio, en igualdad de condiciones con las demás, de todos los derechos humanos y libertades fundamentales."

Eso es, los ajustes razonables son las modificaciones que deben tomarse al advertirse una situación de desventaja o vulneración, es decir, una barrera que genere discapacidad, sin embargo, estas se encuentran condicionadas a no impongan una carga desproporcionada o indebida.

Por ejemplo, en el supuesto de que en el mundo sólo hubiera una persona con diversidad funcional física o con problemas de movilidad y llevase un juicio frente a un tribunal, sin embargo este se encuentra en la planta alta de un edificio; un apropiado ajuste razonable podría ser que el juicio se declinara a un Tribunal que se encuentre en la planta baja del edificio judicial, pues resulta ser una solución menos onerosa y tardada que construir un elevador, lo cual, podría ser desproporcionado por el tiempo, esfuerzo y gasto para la administración de justicia, habida cuenta de que existen otras formas de solucionar la problemática y para los efectos del ejemplo, solo un individuo sería beneficiado.

Es por esto, que el Juez al estudiar el caso concreto y advertir que la sentencia tradicional representa una barrera que genera discapacidad para una de las partes en el juicio, debe realizar un ajuste razonable atendiendo al caso concreto y las circunstancias únicas y particulares de la persona, pues resulta imperativo que se tengan presentes las circunstancias y necesidades de la persona a la que se dirige.

Al respecto, puede consultarse la tesis aislada con número de registro digital 2018631, bajo el rubro: "DERECHO HUMANO DE ACCESO A LA JUSTICIA EN CONDICIONES DE IGUALDAD DE LAS PERSONAS CON DISCAPACIDAD. EL ESTADO DEBE GARANTIZARLO EN SUS DIMENSIONES JURÍDICA, FÍSICA Y COMUNICACIONAL."

Dado que lo que se busca es que se proporcionen los ajustes razonables necesarios para el tipo de diversidad funcional de la persona se especifican algunos ejemplos de ajustes razonables:

\section{- Ajustes razonables en el caso de discapacidad mental o intelectual}

En este caso, el ajuste razonable es emitir una sentencia complementaria a la tradicional con formato de lectura fácil, el cual, no es un ajuste desproporcionado, puesto que lo que representa para la autoridad es un mínimo esfuerzo de elaborar una sentencia complementaria y usar papelería con la que ya cuenta. 
La sentencia con formato de lectura fácil se encuentra dirigida a las personas con discapacidad para leer o comprender la sentencia tradicional, al emitirla el Juez mediante un lenguaje simple y directo, sin tecnicismos y sin conceptos abstractos, comunica al ciudadano el resultado final de la controversia y sus alcances. ${ }^{1}$

Esta sentencia se emite de forma complementaria a la sentencia tradicional, además si bien se ha hecho referencia con anterioridad a los requisitos legales de la sentencia tradicional, la sentencia con formato de lectura fácil no se encuentra regulada en ninguna legislación y mucho menos tiene requisitos establecidos en la ley.

Los operadores jurídicos al elaborar las sentencias dividen la resolución en los siguientes apartados:

1. Datos de la autoridad: Lugar, fecha y tribunal.

2. Datos de identificación: En el que se indica el número de expediente y el nombre de la parte actora y parte demandada.

3. Relación sucinta de los hechos: de forma sintetizada se describen los hechos en los que se funda la demanda interpuesta, y las manifestaciones realizadas por la parte demandada -en su caso-, conformando así la litis.

4. Competencia: se precisan las disposiciones legales que otorgan la facultad a la autoridad de emitir el fallo.

5. Vía: se expresan los motivos por los cuales procede la vía en la que fue interpuesta la demanda.

6. Marco jurídico: se mencionan los instrumentos legales internacionales, nacionales o estatales en los que se fundara la decisión judicial, y se puede incluir en este apartado la jurisprudencia y criterios aplicables al caso en estudio.

7. Razonamiento jurídico: es la parte medular de la sentencia, en este apartado se identifican los hechos, si estos se probaron o no, valorando las pruebas ofrecidas por las partes, razonado y motivando el porqué de la decisión.

8. Conclusiones: en este apartado se encuentran los resultados del estudio de la controversia y sus alcances legales.

9. Resolutivos: se hace referencia en forma concreta a los puntos resueltos en el fallo que se emite, entre otros puntos, tales como, si se probó o no la acción, las consecuencias de declarar probada o no la acción, y el archivo del juicio.

10. Firmas de los funcionarios judiciales,

La sentencia de lectura fácil debe de ser emitida con todos los requisitos señalados, sin embargo estos deben de estar redactados sin separaciones entre rubros, pero con las siguientes características:

- Debe ser breve, concisa y precisa, sin sobreabundar en aspectos que no tienen trascendencia en la causa, ya que las sentencias tradicionales suelen ser extensas.

- Deben de fundarse y motivarse puntualmente, ya que las decisiones deben sostenerse por sí solas, es decir, las razones jurídicas deben de ser tan claras y veraces, que no quede duda que no había otra forma de fallar.

1 Crf. Gaceta del Semanario Judicial de la Federación, $1^{a}$ CCCXXXIX/2013 (10a.), décima época, libro 1, diciembre de 2013, tomo I, página 536, Registro 2005141, de rubro: "SENTENCIA CON FORMATO DE LECTURA FÁCIL. EL JUEZ QUE CONOZCA DE UN ASUNTO SOBRE UNA PERSONA CON DISCAPACIDAD INTELECTUAL, DEBERÁ DICTAR UNA RESOLUCIÓN COMPLEMENTARIA BAJO DICHO FORMATO." 
- No debe contener conceptos abstractos y tecnicismos, es decir, De acuerdo con el diccionario de la Real Academia Española es:

"separar por medio de una operación intelectual un rasgo o una cualidad de algo para analizarlos aisladamente o considerarlos en su pura esencia o noción.”

- Emplear un tipo de letra claro y en tamaño accesible.

- Tener en cuenta que solo se redacta para la persona a quien se dirige la sentencia, por lo que se debe usar su nombre.

- Los párrafos deben de estar separados para tener mayor claridad en la lectura.

- Se puede hacer uso de ejemplos para exponer de mejor manera las ideas.

Si bien, en este artículo se ha abordado la sentencia con formato de lectura fácil en el supuesto de que se trate de personas con diversidad funcional, este caso no es el único en el que se puede emitir este tipo de sentencias, puesto que siempre se pueden realizar si el operador jurídico lo considera al detectar los siguientes supuestos: Débiles sociales, personas de edad avanzada, menores de edad, entre otros.

Al respecto, puede consultarse la tesis aislada con número de registro digital 2005141, bajo el rubro: "SENTENCIA CON FORMATO DE LECTURA FÁCIL. EL JUEZ QUE CONOZCA DE UN ASUNTO SOBRE UNA PERSONA CON DISCAPACIDAD INTELECTUAL, DEBERÁ DICTAR UNA RESOLUCIÓN COMPLEMENTARIA BAJO DICHO FORMATO.”

\section{-Ajustes razonables en el caso de discapacidad sensorial visual.}

En estos casos, puede emitirse de igual forma la sentencia con formato de lectura fácil si el caso concreto lo requiere, además, en estos aspectos debe atenderse al grado de diversidad funcional que cuenta la persona, si este es leve pueden realizarse los siguientes ajustes: Imprimir la sentencia tradicional o en formato de lectura fácil con un tipo de letra que sea clara, con un tamaño de letra que pueda observarse sin esfuerzo, esta medida ya es usada en las labores diarias con los operadores jurídicos, pues resulta ser la solución obvia esta problemática.

En caso de que la diversidad funcional visual sea grave, puede requerirse de otros ajustes, tales como la lectura de la sentencia en sede judicial o proporcionarle un medio electrónico para que conserve un archivo de audio, o apoyarse de instituciones públicas para la traducción de la sentencia tradicional o en su caso de la sentencia con formato de lectura fácil en braille.

En ese tenor, puede consultarse la tesis aislada con número de registro digital 2009152, bajo el rubro: "PERSONAS CON DISCAPACIDAD VISUAL. ATENTO A SUS DERECHOS HUMANOS, LAS AUTORIDADES JURISDICCIONALES ENCARGADAS DE ADMINISTRAR JUSTICIA, PUEDEN INSTAURAR EL SISTEMA DE ESCRITURA BRAILLE EN EL PROCEDIMIENTO POR SER UNO DE LOS MEDIOS DE COMUNICACIÓN CONTEMPLADOS EN "LA CONVENCIÓN SOBRE LOS DERECHOS DE LAS PERSONAS CON DISCAPACIDAD” Y EN LA LEY GENERAL PARA LA INCLUSIÓN DE ÉSTAS, PARA LOGRAR SU INCLUSIÓN AL PROCESO, POR PROPIO DERECHO Y EN UN PLANO DE IGUALDAD.” 


\section{- Ajustes razonables en el caso de discapacidad sensorial auditiva.}

El operador jurídico, puede auxiliarse de instituciones públicas para que ordene la notificación de la sentencia con apoyo de intérpretes de Lengua de Señas Mexicana.

Tiene fundamento en la obligación de los terceros en la cooperación con las labores del tribunal, más si se trata de autoridades, que como se expresó, en el ámbito de sus competencias, deben de proteger, respetar y garantizar los derechos humanos de las personas con discapacidad.

\section{- Ajustes razonables concomitantes.}

Como ya se ha expresado, el operador jurídico debe de atender a la diversidad humana, misma que es cambiante y distinta en cada persona, por ello, debe de tener especial cuidado en establecer el tipo o tipos de discapacidad que tiene la persona, para poder realizar uno o varios ajustes razonables, mismos que no tienen limitación en número y pueden válidamente coexistir.

\section{- Otros ajustes razonables.}

Los ajustes razonables expresados son sólo algunas sugerencias por el tipo de discapacidad, pero no son los únicos, el límite de los ajustes razonables es únicamente la creatividad de los operadores jurídicos, ya que puede auxiliarse de medios que tiene a su alcance como la tecnología, intérpretes o instituciones, todo con la única finalidad de que el ajuste razonable que considere tenga plena efectividad.

Por ejemplo, el CPCT contempla la notificación de las sentencias por medios electrónicos, y derivado de la pandemia mundial por el brote de coronavirus COVID-19 decretada por la Organización Mundial de la Salud decretada en El 11 de marzo de 2020, el uso de medios electrónicos para notificar se intensificó, notificando vía correo electrónico o por WhatsApp; ello abre la posibilidad a que si se requiere, puede adjuntarse a la sentencia tradicional e incluso a la sentencia con formato de lectura fácil: un archivo de audio o video, en el que el operador jurídico o intérprete explique el fallo emitido.

\section{e. Evitar re victimización o discriminación.}

Las personas con discapacidad han sido son objetos de protección, sin embargo, en el nuevo paradigma de discapacidad establecido en el modelo social, es imperativo respetar su dignidad como persona, es decir, considerarlos sujetos de protección.

Comúnmente la discriminación de las personas con discapacidad surge de manera involuntaria y con ánimos de protegerlas, pensando de facto que "no pueden” por sí mismos, sin ni siquiera darles oportunidad de demostrar lo contrario, es por ello por lo que, al momento de establecer los ajustes razonables debe considerarse que este ajuste no represente una acción de discriminación o re victimización de las personas.

Esto es, no es un ajuste razonable notificar a persona distinta que la persona con diversidad funcional y dar cumplida la obligación de la autoridad, puesto que no deben conllevar a que sean terceros quienes sustituyan a las personas con discapacidad.

De igual forma, la sentencia tradicional y en su caso, la sentencia con formato de lectura fácil no puede incluir estereotipos o prejuicios personales en su redacción, ya que en todo momento se debe 
de privilegiar la dignidad inherente de las personas, este impedimento también puede trasladarse a términos incorrectos para dirigirse a la diversidad funcional de la persona, como lo es: cieguito, sordomudo, minusválido, etc.

Finalmente, y no menos importante, el operador jurídico no debe de caer en el formalismo de requerir a las personas para que justifiquen su diversidad funcional con dictámenes médicos u otros documentos para estar en aptitud de realizar ajustes razonables, pues ello es visiblemente una práctica que genera re victimización de las personas.

\section{CONCLUSIONES}

Desde la antigüedad se ha vulnerado sistemáticamente los derechos de las personas con diversidad funcional y en la actualidad, aún con la aprobación el trece de diciembre de dos mil seis de la CDPD y su Protocolo Facultativo, es tarea de todos resarcir esta deuda histórica, protegiendo y respetando los derechos humanos de las personas con discapacidad.

Los operadores jurídicos deben de cumplir con su obligación de procurar la operatividad de la CDPD y velar por el respeto de las personas con discapacidad en el ámbito jurisdiccional, es decir, buscar mediante ajustes razonables que las personas tengan acceso a la justicia y a todos sus derechos; ya que es deber de la Autoridad impartir justicia y garantizar que todos y cada uno de los ciudadanos, ejerzan sus derechos en igualdad de condiciones.

En virtud de que la impartición de justicia solo puede ser accesible y confiable para los ciudadanos, si todos, incluidos los que tienen una diversidad funcional, pueden conocer y comprender el contenido y los alcances jurídicos de las resoluciones, por tanto, los operadores jurídicos deben respetar la diversidad humana y atender a esta al momento en el que se dicta una sentencia tradicional, advirtiendo si es necesario realizar ajustes razonables, ya sea emitiendo una sentencia complementaria en formato de lectura fácil, auxiliarse de intérpretes, apoyarse en la tecnología, entre otros; ello, con la única finalidad de que toda persona que acuda, tenga acceso al contenido de la resolución que se emita.

Con los lineamientos proporcionados, el operador jurídico podrá analizar cada asunto que tenga para su estudio, atender a su obligación internacional y nacional, protegiendo los derechos humanos de las personas con diversidad funcional evitando barreras que generen discapacidad.

De actuar de forma distinta, constituye una franca discriminación con motivo de discapacidad, ya que los operadores jurídicos, deben evitar discriminar por razón de discapacidad, pues, ello constituye un agravio a la dignidad de las personas.

Este documento abordó los ajustes razonables que pueden ser necesarios al momento de dictar sentencia, principalmente de la necesidad de emitir la sentencia con formato de lectura fácil, sin embargo, la obligación no se limita a esta etapa procesal y el operador jurídico también puede establecer ajustes al procedimiento que sean eficaces para que las personas con discapacidad ejerzan plenamente sus derechos dentro del juicio. 


\section{REFERENCIAS}

\section{Publicaciones.}

1. Berdeja Rivas, M., Martínez Prats, G., \& Silva Hernández, F. (2020). Transparencia y acceso a la información pública ante situaciones de pandemia. Publicaciones E Investigación, 14(2). https:// doi.org/10.22490/25394088.4351

2. Carreón Castro, María del Carmen. (2019). Guía para la inclusión de personas con discapacidad: Acceso a la justicia y derechos político-electorales. Ciudad de México, México: Tribunal Electoral del Poder Judicial de la Federación.

3. Gómez Lara, Cipriano. (2015). Derecho Procesal Civil. México: Oxford.

4. INEGI. (2021). Población con limitación o discapacidad por entidad federativa según sexo, 2020. INEGI Sitio web: https://www.inegi.org.mx/app/tabulados/interactivos/?pxq=Discapacidad Discapacidad_01_ab15caa8-8870-4e16-b4a9-210dade5fafc

5. OMS. Organización Mundial de la Salud. 2001. Clasificación Internacional del Funcionamiento de la Discapacidad y de la Salud: CIF.

6. Palacios, Agustina, (2008), El modelo social de discapacidad: orígenes, caracterización y plasmación en la Convención Internacional sobre los Derechos de las Personas con Discapacidad, Madrid, España, Grupo editorial CINCA.

7. Real Academia Española: Diccionario de la lengua española, 23. ${ }^{a}$ ed., [versión 23.3 en línea]. https://dle.rae.es/abstraer, 18/04/2021

8. Leyes e instrumentos jurídicos

9. Amparo en revisión. (2019). Ponente: Ministro Alfredo Gutiérrez Ortiz Mena. Véase: https:// www2.scjn.gob.mx/ConsultaTematica/PaginasPub/DetallePub.aspx?AsuntoID=190473

10. Código de Procedimientos Civiles para el Estado de Tabasco (1997). Periódico oficial suplemento 5697.Tabasco, México.

11. Convención de los Derechos de las Personas con Discapacidad y protocolo facultativo. Decreto de Aprobación publicado en el Diario Oficial de la Federación, 24 de octubre de 2017. Ratificado por México, 17 de enero de 2008.

12. CPEUM. Constitución Política de los Estados Unidos Mexicanos. 2019. México: Cámara de Diputados.

13. Ley General para la inclusión de las Personas con Discapacidad. 2018. México: Cámara de Diputados.

\section{Jurisprudencia}

14. Gaceta del Semanario Judicial de la Federación, 1ª CCCXXXIX/2013 (10a.), décima época, libro 1, diciembre de 2013, tomo I, página 536, Registro 2005141, de rubro: "SENTENCIA CON FORMATO DE LECTURA FÁCIL. EL JUEZ QUE CONOZCA DE UN ASUNTO SOBRE UNA PERSONA CON DISCAPACIDAD INTELECTUAL, DEBERÁ DICTAR UNA RESOLUCIÓN COMPLEMENTARIA BAJO DICHO FORMATO.

15. Gaceta del Semanario Judicial de la Federación. Libro 18, mayo de 2015, Tomo III, XVII.1o.C.T.1 CS (10a.), Décima Época, Registro digital: 2009152, de rubro: PERSONAS CON DISCAPACIDAD VISUAL. ATENTO A SUS DERECHOS HUMANOS, LAS AUTORIDADES JURISDICCIONALES ENCARGADAS DE ADMINISTRAR JUSTICIA, PUEDEN INSTAURAR EL SISTEMA DE ESCRITURA BRAILLE EN EL PROCEDIMIENTO POR SER UNO DE LOS MEDIOS DE COMUNICACIÓN CONTEMPLADOS EN "LA CONVENCIÓN SOBRE LOS DERECHOS DE LAS PERSONAS CON DISCAPACIDAD" Y EN LA LEY GENERAL PARA LA INCLUSIÓN DE ÉSTAS, PARA LOGRAR SU INCLUSIÓN AL PROCESO, POR PROPIO DERECHO Y EN UN PLANO DE IGUALDAD.

16. Gaceta del Semanario Judicial de la Federación. Libro 61, diciembre de 2018, Tomo I, página 309, 1a. CCXVI/2018 (10a.), Registro digital: 2018631, bajo el rubro: DERECHO HUMANO DE ACCESO A LA JUSTICIA EN CONDICIONES DE IGUALDAD DE LAS PERSONAS CON DISCAPACIDAD. EL ESTADO DEBE GARANTIZARLO EN SUS DIMENSIONES JURÍDICA, FÍSICA Y COMUNICACIONAL. 